\title{
A Surface Network Based on Polytyramine/ Gold Nanoparticles: Characterization, Kinetics, Thermodynamics and Selective Determination of Norepinephrine
}

\author{
Emad A. Khudaish* and Arwa Al-Maskari
}

Department of Chemistry, College of Science, Sultan Qaboos University, P.O. Box 36, PC 123, Al-khoud, Muscat, Sultanate of Oman. *E-mail: ejoudi@squ.edu.om.

\begin{abstract}
A solid-state sensor was fabricated by a spontaneous electrochemical deposition of polytyramine (Ptyr) film onto a glassy carbon electrode (GCE) which was further peripherally supported by gold nanoparticles (AuNPs). The surface materials of the developed sensor (AuNPs.Ptyr-GCE) were characterized by X-ray photoelectron spectroscopy (XPS), electrochemical impedance spectroscopy (EIS), cyclic voltammetry (CV) and differential pulse voltammetry (DPV). The rate constant of charge transfers $\left(k_{\mathrm{ct}}\right)$ of the as-prepared sensor $\left(8.77 \times 10^{-4} \mathrm{~cm} / \mathrm{s}\right)$ was evaluated by fitting the charge transfer resistance $\left(R_{\mathrm{ct}}\right)$ data in the presence of ferric-ferrous hexacyanide redox couple solution, $\left[\mathrm{Fe}(\mathrm{CN})_{6}\right]^{3-4-}$. The voltammetric behavior of norepinephrine (NOR) was confirmed to follow an irreversible reaction mechanism at which the estimated diffusion coefficient value was $7.39 \times 10^{-5} \mathrm{~cm}^{2} / \mathrm{s}$. The sensor showed a large enhancement on NOR oxidation and comparatively lowered its detection limit ( $\left.\mathrm{DL}_{3 \sigma}\right)$ to $0.130 \mu \mathrm{M}(22 \mathrm{ppb})$. It was also applied for selective determination of NOR in the presence of high concentrations of ascorbic acid (AA) and uric acid (UA). The interference study highlighted the great stability of the proposed sensor by generating a similar sensitivity as in the pure NOR solution. The analytical performance of the proposed system was validated successfully for pharmaceutical and biological samples with tolerable recovery percentages.
\end{abstract}

Keywords: Polytyramine; Gold nanoparticles; Norepinephrine; Ascorbic acid and Uric acid.

$$
\text { الانتقائية سطي شبكي من بوليل النورابنفرين التيرامين وذرات النانو لعنصر الذهب : دراسة تشخيص البناء ، الديناميكيا الحركية والحرارية ، عماد خديش و أروى المسكري }
$$

الملخص: بناء مستشعر صلب الحالة بو اسطة التر اكم الالكتروكهربائي لطبقة رقيقة من بوليمر التير امين على سطح قطب الكاربون الزجاجي وتدعيمه بطبقة

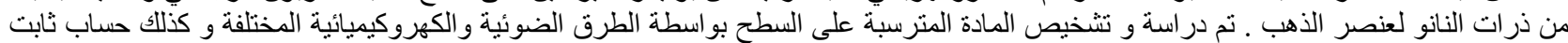

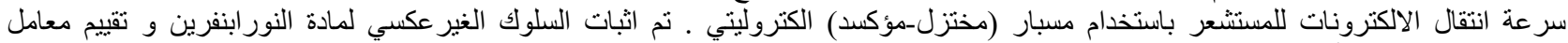

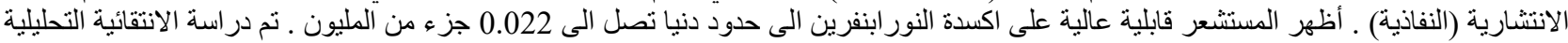

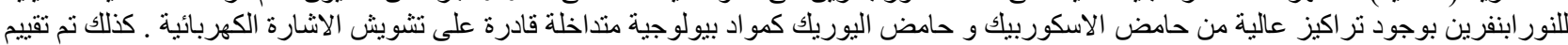

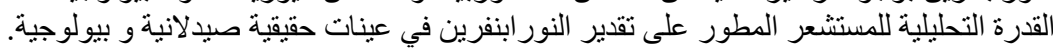
الكلمات المفتاحية: بوليمر التيرامين، نور ابنفرين، ذرات النانو لعنصر الذهب ، حامض الاسكوربيك، حامض اليوريك. 


\section{Introduction}

C onstruction of chemically modified electrodes based on the incorporation of, or a coating of, specific conducting materials is one of the central research activities of the past decades [1,2]. The selection and characterization of modified surface materials are playing important roles in testing the stability, the reproducibility and the analytical performance of certain electro-active substances. The deposition of polymeric nanocomposite materials onto electrode surfaces by electrochemical means is an interesting topic in terms of producing a uniform coating with layers of specific thickness [3,4].

Tyramine (tyr) has received considerable attention as an ideal monomer for electrochemical deposition due to the presence of a free amino functional group that simplifies doping of organic or inorganic materials $[5,6]$. Moreover, the phenolic functionality can be easily oxidized for initiation of a polymeric reaction and formation by propagation steps for a final generation of the polymer [7,8]. Polytyramine (Ptyr) film deposited on different substrates under various experimental conditions has been studied to understand its structure, composition, thermal and mechanical properties, along with its conductivity for sensing applications [9-11].

There has been great interest in nano-sized elements such as gold nanoparticles (AuNPs) for the fabrication of electrochemical sensors due to their outstanding physical and chemical properties, comprising their small size, high catalytic activity, large surface area, and their having compatible environment [12,13]. Moreover, electrode modification by doping of AuNPs onto a polymeric moiety such as Ptyr can be functionalized for improving the electronic conductivity of surface materials which enhances the kinetics of the electron transfer process. The presence of a free amino group makes Ptyr an attractive structure for further modification by attachment of an active electron mediator such as AuNPs. The resulting AuNPs. Ptyr-GCE modified electrode is expected to have a characteristic active surface area, a larger adsorption domain, and hence a greater catalytic capacity.

Catecholamines are vital neurotransmitters that control the physiological processes in human bodies by regulating communication within the neural network [14]. They are released from noradrenergic neurons in the central nervous system (CNS) and sympathetic nervous system (SNS) for many neurophysiological processes such as monitoring heart rate, fatty acid placement, stress sensing, body temperature, learning, and memory $[15,16]$. Damage in secretion or uptake of neurotransmitters is known to cause neurodegenerative diseases and psychiatric disorders [17].

NOR is one significant transmitter which has a strong influence on attention and response activities within the brain, is a blood pressure controller, and regulates emotional excitement and mood disorders [18]. It has an important role in the treatment of hypertension, bronchial asthma, organic heart disease and myocardial infarction, and in cardiac surgery [19]. Abnormal levels of NOR in plasma and urine are utilized as a biomarker for several diseases such as hypertension, diabetes mellitus ketoacidosis, neuroblastoma and Parkinson's disease [20,21]. Therefore, a large number of methods have been developed for the sensitive and selective quantification of trace amount of NOR in biological samples or pharmaceutical formulations [22,23]. A nonconventional method for rapid detection with great precision and reproducibility has been an urgent demand for neurotransmitter analysis that includes the application of electrochemical sensors with highly reactive surface materials [24,25]. Electrochemical approaches applying various systems of interest have been proposed for selective and sensitive analysis, based on active surface modifications including the attachment of metal nanoparticles to conducting polymers [26], surfactant assisted metal oxide nanoparticles [27], self-assembled L-cysteine/AuNPs/MWCNT [28], and a graphene modified electrode [29], among many others.

In the present work, the attachment of AuNPs has been achieved by direct surface casting a drop of AuNPs over the pre-fabricated (Ptyr-GCE) surface. The rich $\pi$-bonding electrons of the polymer backbone attract strongly to electrons of gold atoms in the outer orbitals. The resulting modified electrochemical system (AuNPs.Ptyr-GCE) was studied to explore its composition, stability and electrochemical performance for the selective determination of norepinephrine (NOR) in the presence and absence of electrochemically active interference biological species such as ascorbic acid (AA) and uric acid (UA). Furthermore, the analytical performance of the proposed sensor was tested for real samples (pharmaceutical ampoule solution and plasma blood).

\section{Experimental section}

\subsection{Apparatus and chemicals}

A BAS 50W Potentiostat was used to control all electrochemical measurements that were conducted in a threeelectrode cell. A bare GCE (before modification) was used as the working electrode (WE), a platinum coil as the counter electrode (CE) and $\mathrm{Ag} / \mathrm{AgCl} / \mathrm{KCl}_{\text {(sat.) }}$ as the reference electrode (RE). The potentiostat and electrodes were purchased from BAS (Bioanalytical System, West Lafayette, IN, USA). The WE was regularly polished prior to each experiment to a mirror surface using a polishing cloth and alumina slurry $(5.0$ and $1.0 \mu \mathrm{m})$, rinsed with acetone and washed fully with distilled water, then ultra-sonicated in water for $5 \mathrm{~min}$ using JAC Ultra Sonic (LABKOREA INC, Korea), and finally rinsed thoroughly with distilled water.

The tyramine (tyr) monomer, norepinephrine (NOR), ascorbic acid (AA), uric acid (UA), potassium ferrohexacyanate, $\mathrm{K}_{4}\left(\mathrm{Fe}(\mathrm{CN})_{6}\right.$, potassium ferrihexacyanate, $\mathrm{K}_{3}\left(\mathrm{Fe}(\mathrm{CN})_{6}\right.$, and sulfuric acid $\left(\mathrm{H}_{2} \mathrm{SO}_{4}\right)$, all were of analytical grades purchased from Sigma-Aldrich Chemie, Germany. Potassium orthophosphate $\left(\mathrm{KH}_{2} \mathrm{PO}_{4}\right)$ and 
dipotassium phosphate $\left(\mathrm{K}_{2} \mathrm{HPO}_{4}\right)$ were obtained from BDH, UK. Gold nanoparticles (AuNPs) of 30 nm size come with a citrate ligand (Nanopartz Inc., USA). A moderately alkaline background electrolyte $(\mathrm{pH}=7.4)$ made of $0.1 \mathrm{M}$ phosphate buffer solution (PBS) was used for selective determination of NOR in the electrochemical cell $($ size $=20$ $\mathrm{mL}$ ) which was degassed for $10 \mathrm{~min}$ prior to measurement with oxygen-free nitrogen gas, and which was blanketed throughout the experiment.

\subsection{Fabrication of the surface network}

The proposed AuNPs.Ptyr-GCE surface network was fabricated by deposition of Ptyr onto the clean GCE via reversible voltammetric cycling followed by a drop casting of $20 \mu \mathrm{L}$ AuNPs. The electrochemical deposition of the Ptyr was achieved by continuous scanning of the WE potential between $0 \mathrm{mV}$ and $1400 \mathrm{mV} \mathrm{vs} . \mathrm{Ag} / \mathrm{AgCl}$ at $50 \mathrm{mV} / \mathrm{s}$ for 30 scans ( 15 cycles) in $0.1 \mathrm{M}$ of $\mathrm{H}_{2} \mathrm{SO}_{4}$ containing $20 \mathrm{mM}$ tyr monomer. The deposition time limit for controlling the thickness of the Ptyr film is a crucial factor to build up a sensitive surface material possessing a good conductivity. Therefore, lowering the number of repetitive cycles to 15 was sufficient to fabricate a thin and stable platform for doping electroactive materials such as AuNPs and presenting an active surface for electron shuttling with the electrode substrate. The electrode sensitivity decreases dramatically with a larger deposition time limit of Ptyr (above 20 cycles), in agreement with previous experimental data describing the surface resistivity, passivation and limitation of active area due to increasing film thickness [30].

\subsection{Characterization of the surface network}

The surface materials of the modified electrode were essentially identified (structure, composition and reactivity) using various analytical tools. An X-ray Photoelectron Spectroscopy (XPS) machine (Omicron Nanotechnology XPS system, Germany) was employed to determine the composition of materials deposited onto the GCE. The obtained XPS spectra of individual components were de-convoluted using a Gaussian Lorentzian function after background subtraction with a Shirley function in Casa XPS software (Casa Software Ltd, UK). The binding energies were calibrated with respect to a adventitious C 1s feature at $284.6 \mathrm{eV}$.

Electrochemical impedance spectroscopy (EIS) experiments using a Bi-Potentiostat PC-14 (Gamry, USA) were conducted to identify the resistivity of the deposited materials on the electron transfer processes. The EIS data were recorded in a three-electrode cell containing $5 \mathrm{mM}$ of $\left[\mathrm{Fe}(\mathrm{CN})_{6}\right]^{3-/ 4-}$ solution within a frequency range of between 100 $\mathrm{kHz}$ to $1 \mathrm{~Hz}$ at an amplitude of $5 \mathrm{mV}$. Randle's equivalent circuit was used to demonstrate the electrochemical properties at the solid/electrolyte interface at open circuit potential.

Cyclic Voltammetry (CV) and Differential Pulse Voltammetry (DPV) techniques (BAS Software, USA) were used for electrochemical deposition of the modified electrode, reactivity and selectivity tests, and analytical performance for sensitivity of determination of NOR in artificial and real samples.

\subsection{Preparation of real samples}

A noradrenaline ampoule $(1 \mathrm{mg} / \mathrm{mL})$ and plasma blood samples were obtained from SQU hospital, Muscat, Oman. The drug solution was diluted 10 times with PBS $(0.1 \mathrm{M}$ of $\mathrm{pH}=7.4)$ to prepare a $0.591 \mathrm{mM}$ stock solution which was applied directly for DPV measurements of NOR. On the other hand, the plasma blood was diluted 3 times with PBS and the standard addition method for as-prepared $0.5 \mathrm{mM}$ of NOR was applied. The recovery percentage of NOR in both real samples was computed to evaluate the sensitivity and reliability of the proposed sensor.

\section{Results and discussion}

\subsection{Fabrication of the surface network materials}

Electrochemical deposition of Ptyr film on the GCE surface was obtained by repetitive voltammetric scanning of 30 segments (15 cycles) using the cyclic voltammetry (CV) method. The electrode potential was reversibly stepped between 0 and $1400 \mathrm{mV}$ vs $\mathrm{Ag} / \mathrm{AgCl}$ at a rate of $50 \mathrm{mV} / \mathrm{s}$ in an electrochemical cell containing $20 \mathrm{mM}$ of tyr monomer dissolved in $0.1 \mathrm{M} \mathrm{H}_{2} \mathrm{SO}_{4}$. Figure 1 shows an irreversible anodic peak for tyr oxidation at $1175 \mathrm{mV}$ (for the first cycle) which decreases significantly at the preliminary four successive cycles. Moreover, the anodic peak potential is shifted negatively to $1125 \mathrm{mV}$ in the fourth cycle. The above trend suggests a surface passivation due to the generation of low conductivity short oligomers. The growth of the polymeric film in the subsequent cycles from cycle 5 (dotted black) to cycle 15 (solid black) as shown in the inset is associated with reduction of the surface resistivity, apparent by a spontaneous increase of the anodic peak current at $1135 \mathrm{mV}$. The propagation of the polymer (Ptyr) is predominantly carried out by the formation of cationic radical intermediates due to an oxidation reaction of the phenolic group present in the tyr monomer [31]. The phenoxy cationic radical produced in the initiation step undergoes a dimerization reaction by attacking a new tyr molecule (linkage via the ortho position in the aromatic ring). With subsequent cycling, the oligomerization process is continued to form an insoluble propagated polymer that is deposited onto the electrode surface in a mechanism consistent with those demonstrated for Ptyr deposition at sputtered [32] and graphite [33] electrodes. In the present experimental conditions, the 15 repetitive cycles were appraised to build a thin polymeric film on the electrode surface. It was observed that the anodic peak current adopted nearly a constant value above 15 cycles, indicating the growth of a thicker film. The thickness and the amount of Ptyr deposited on the 
electrode surface are directly affected by the nature of the electrode substrate, the concentration of tyr monomer and electrolyte composition (mostly the $\mathrm{pH}$ ), the number of potential cycles and scan rates. It should be noted that the oxidation of tyr in an acidic medium results in the formation of Ptyr with a rich number of free cationic amino groups (one per a chain). Accordingly, the experimental conditions and data presented in Figure 1 were selected to generate a thin Ptyr platform film for doping active surface materials such as gold nanoparticles (AuNPs). The above pattern of fabrication increases the electrode surface area and enhances the electron transfer kinetics with the targeted electroactive species. For this task, a drop of $20 \mu \mathrm{L}$ AuNPs was mechanically added onto the moiety of the fabricated Ptyr modified surface.

The proposed sensor (AuNPs.Ptyr-GCE) was characterized using various analytical tools and finally applied for the selective determination of NOR in artificial and real samples.

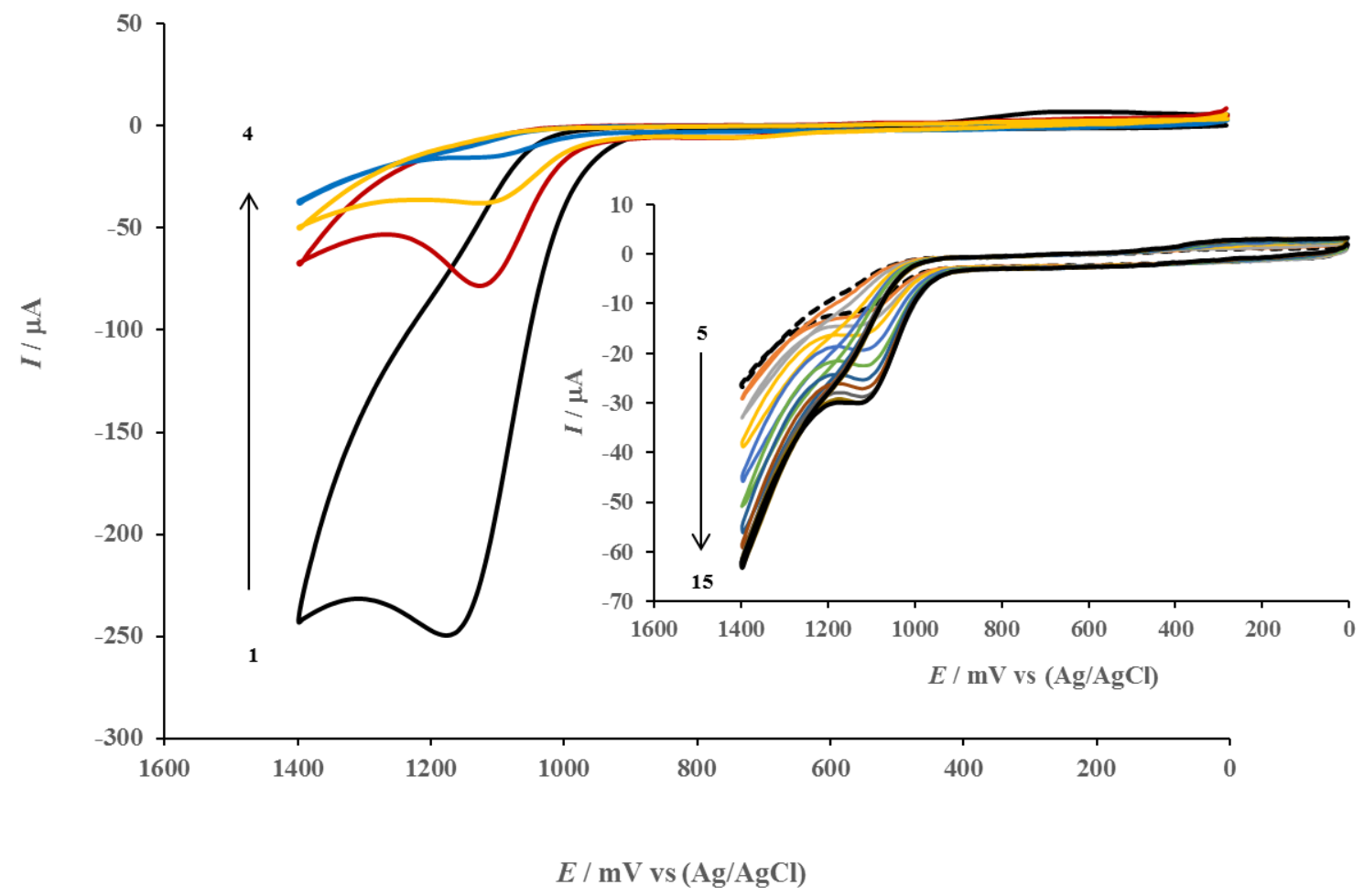

Figure 1. Reversible potentiodynamic waves (15 cycles) using GCE in $20 \mathrm{mM}$ of acidified tyr monomer. The electrode potential scanned between 0 and $1400 \mathrm{mV}$ at a rate of $50 \mathrm{mV} / \mathrm{s}$.

\subsection{Characterization of surface materials}

\subsubsection{XPS studies}

The XPS core level spectra of $\mathrm{C}$ 1s peaks obtained from different samples are shown in Figure 2. The XPS spectra of a bare GCE surface shown in Figure 2 (A) produces approximately an equal percentage of $(\mathrm{C}-\mathrm{C}) /(\mathrm{C}-\mathrm{H}) \mathrm{sp}^{2}$ hybridization obtained at $(284.5 \mathrm{eV})$ and $\mathrm{sp}^{3}$ hybridization at $(285.0 \mathrm{eV})$, respectively. The structure and percentage of $(\mathrm{C}-\mathrm{C}) /(\mathrm{C}-\mathrm{H})$ function are changed upon deposition of the polymer and came as a single peak at its preference position of $284.6 \mathrm{eV}$ with $93.6 \%$ as shown in Figure 2 (B). Two extra convoluted peaks were obtained at $285.7 \mathrm{eV}(21.3 \%)$ and $287.1 \mathrm{eV}(12.6 \%)$ characterized for functional groups of $(\mathrm{C}-\mathrm{N}) /(\mathrm{C}-\mathrm{O})$ and $(\mathrm{C}=\mathrm{O})$, respectively. Upon casting of the AuNPs, the $\mathrm{C} 1 \mathrm{~s}$ spectra for the fabricated (AuNPs.Ptyr-GCE) shows some distinctive features on the nature of surface functionalities in terms of binding energies and percent concentrations. Figure 2 (C) depicts three convoluted peaks obtained at $284.8 \mathrm{eV}(79 \%), 285.9 \mathrm{eV}(38.3 \%)$ and $289 \mathrm{eV}(32.1 \%)$ assigned to $(\mathrm{C}-\mathrm{C}) /(\mathrm{C}-\mathrm{H}),(\mathrm{C}-\mathrm{N}) /(\mathrm{C}-\mathrm{O})$, and $(\mathrm{C}=\mathrm{O})$, respectively. 

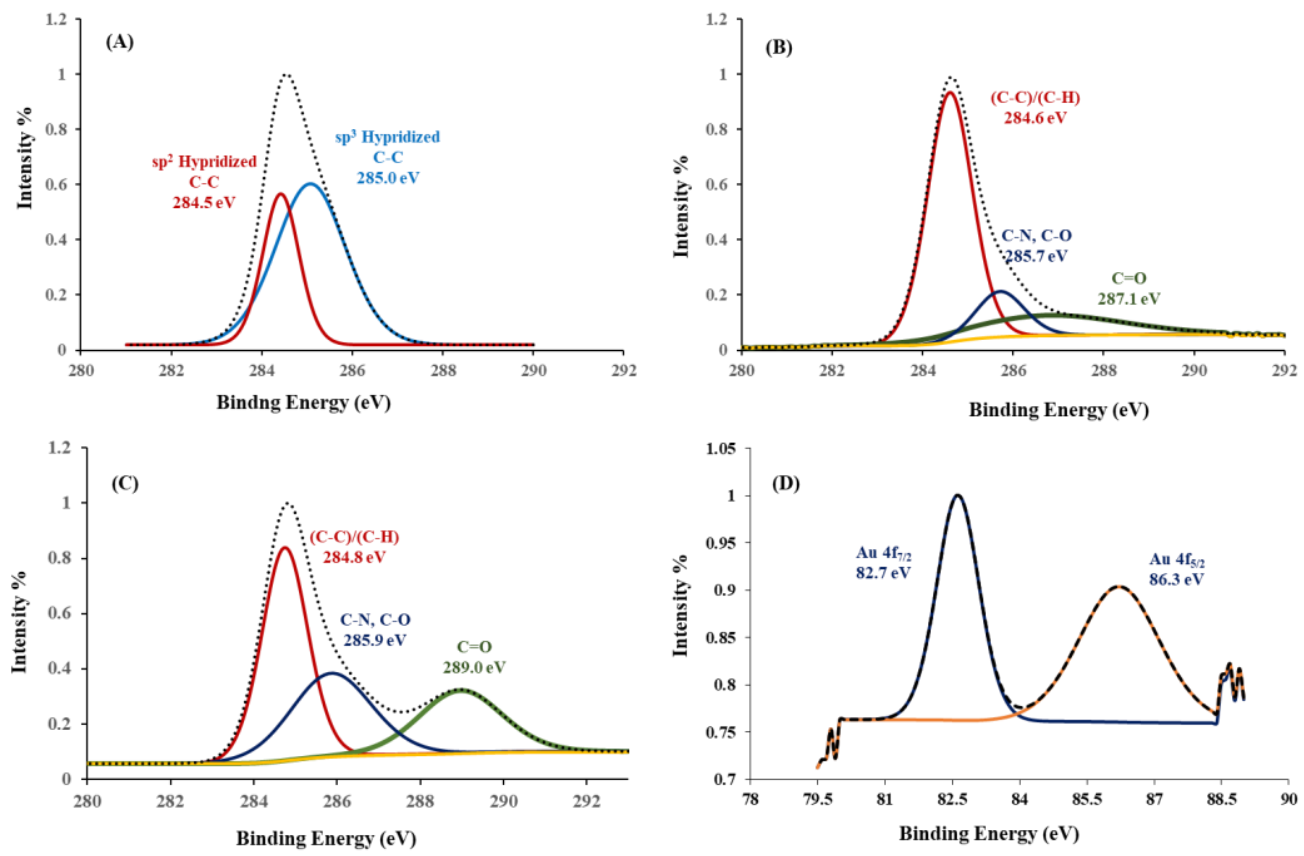

Figure 2. XPS spectra for surface samples; (A) C 1s of pristine GCE, (B) C 1s of Ptyr-GCE, (C) C 1s of AuNPs.PtyrGCE, and (D) Au $4 \mathrm{f}$ of AuNPs onto Ptyr moiety.

The above characteristic topographies presented in Figure 2 (B) and (C) are evidence for successful deposition of Ptyr and the construction of the proposed (AuNPs.Ptyr-GCE) sensor. The presence of AuNPs on the surface materials is confirmed by the high resolution XPS spectra for the Au 4f pattern shown in Figure 2 (D). Two deconvoluted peaks at electronic states of $82.7 \mathrm{eV}\left(\mathrm{Au} 4 \mathrm{f}_{7 / 2}\right)$ and $86.3 \mathrm{eV}\left(\mathrm{Au} 4 \mathrm{f}_{5 / 2}\right)$ [34] were obtained with a spinorbit separation of $3.7 \mathrm{eV}$ confirming the attachment of Au species onto the surface moiety [35]. The experimental data and all features presented in Figure 2 are evidence for successful surface modification and the final preparation of the proposed sensor.

\subsubsection{EIS and electrochemical studies}

The structure of the solid/liquid interface is subject to some limiting factors that affect the reactivity of the fabricated sensors. Restriction factors are centralized by the internal resistance generated by surface modification and can be represented by the impedance of the electrodes under investigation. The internal resistance is composed of three components: charge transfer resistance $\left(R_{\mathrm{ct}}\right)$ which arises by surface activation, the omhic component which is described by the solution resistance $\left(R_{\mathrm{s}}\right)$ due to solution resistivity and the nature of surface materials, and finally the concentration or mass transport resistance (generally considered as a pure diffusion). These important features can be studied efficiently using the electrochemical impedance spectroscopy (EIS) under experimental conditions of a narrow potential window and a wide frequency range.

The Nyquist plot presented in Figure 3(A) demonstrates the applied potential at the open circuit value of a redox probe $\left(5 \mathrm{mM}\right.$ of $\left[\mathrm{Fe}(\mathrm{CN})_{6}\right]^{3-14}$-) which is characterized by both faradaic and non-faradaic processes. The faradaic process is initiated by the surface activation process and defined by the electrode kinetics (fast or slow). Therefore, it is a direct measurement of $\left(R_{\mathrm{ct}}\right)$ and describes the extent of impedance (inhibition) of the electron transfer process at the modified surfaces.

Mathematically, it is inversely proportional to the rate constant of the electron transfer process $\left(k_{\mathrm{ct}}\right)$ induced by surface materials and simply given by $\left(R_{\mathrm{ct}} * k_{\mathrm{ct}}=K\right)$ [36], where $K$ is a constant equal to $0.749 \mathrm{~cm} . \mathrm{ohm} / \mathrm{s}$ for the present experimental conditions, which involve the transfer of a single electron $(\mathrm{n}=1)$ at ambient temperature $(T=298$ $\mathrm{K})$. The non-faradaic process arises due to charging of the double layer capacitance $\left(C_{\mathrm{dl}}\right)$ via electrostatic attraction of ions at the interface satisfied by the value of potential across it. In addition, a typical semicircular curve with resistance zone combines both $\left(R_{\mathrm{ct}}\right)$ and the uncompensated solution resistance $\left(R_{\mathrm{s}}\right)$ imposed by the working electrolyte, both obtained at high frequency. The mass transport process (diffusion) is depicted as a straight line obtained at low frequencies. 


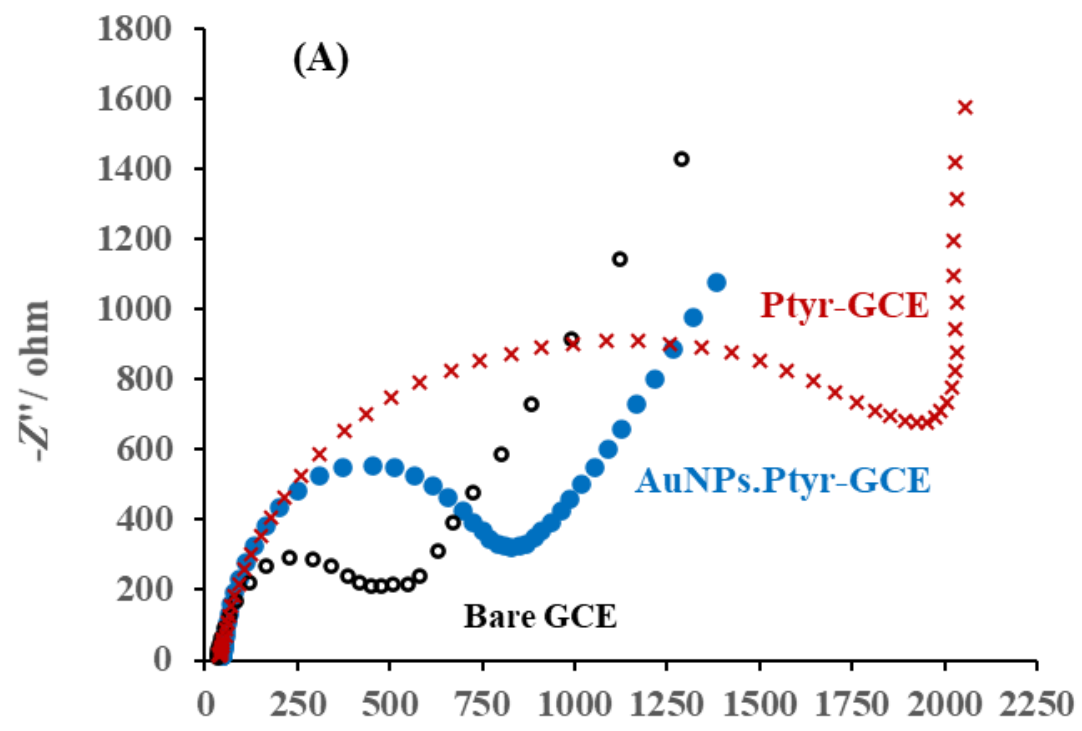

$Z$ '/ohm

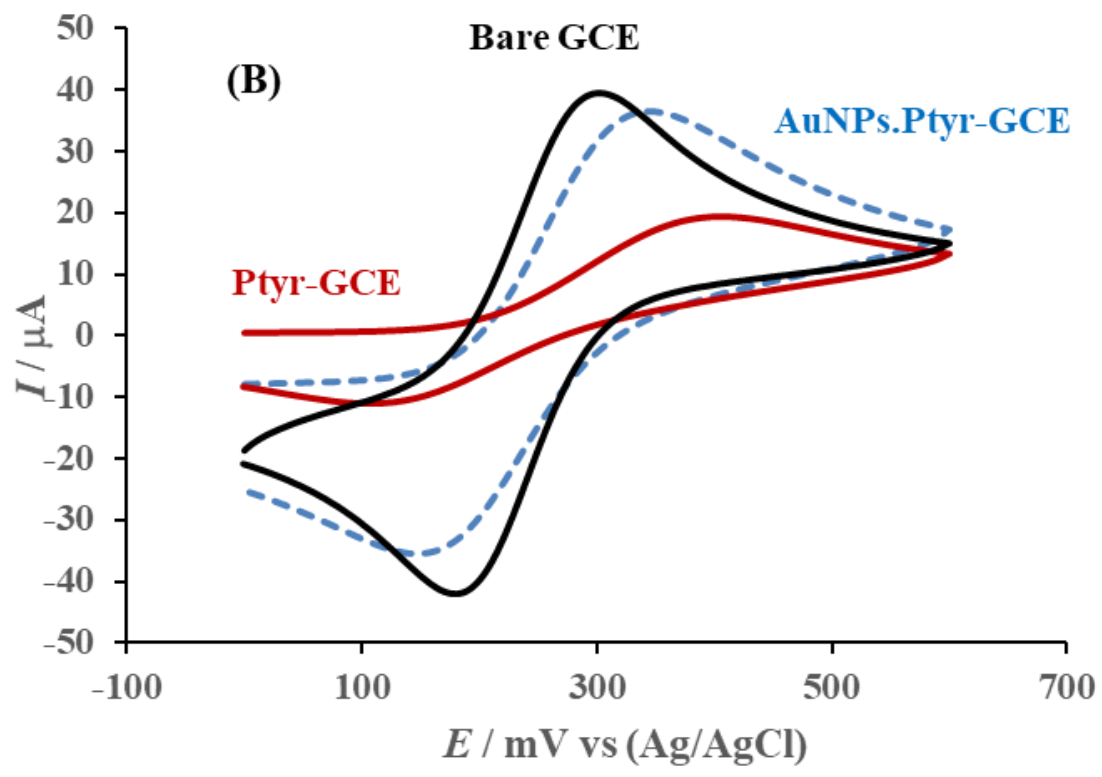

Figure 3. (A) EIS spectra represented by Nyquist plot for bare GCE (black open circle), Ptyr-GCE (red cross) and AuNPs.Ptyr-GCE (blue closed circle) in the presence of $5 \mathrm{mM}\left[\mathrm{Fe}(\mathrm{CN})_{6}\right]^{3-/ 4-}$. (B) CVs for bare GCE (black), PtyrGCE (red) and AuNPs.Ptyr-GCE (blue dotted) in the presence of $5 \mathrm{mM}\left[\mathrm{Fe}(\mathrm{CN})_{6}\right]^{3-/ 4-}$.

The EIS fitting data for all electrodes depicted in Figure 3(A) have different values of $R_{\mathrm{ct}}$ owing to the nature of the surface materials. For instance, the bare GCE (black open circle) produces a value of $470 \Omega$ which increased extremely to $2360 \Omega$ prior to deposition of Ptyr onto GCE (red cross). The value of $R_{\mathrm{ct}}$ obtained for AuNPs.Ptyr-GCE (blue closed circle) is lowered dramatically to $855 \Omega$. Apparently, introducing of AuNPs as a new member of the surface materials improves the kinetics (decreases the surface resistivity) of the fabricated sensor. Consequently, the computed $\left(k_{\mathrm{ct}}\right)$ value for the proposed (AuNPs.Ptyr-GCE) sensor was $8.77 \times 10^{-4} \mathrm{~cm} / \mathrm{s}$, higher by 2.8 times over that $\left(3.18 \times 10^{-4} \mathrm{~cm} / \mathrm{s}\right)$ of the (Ptyr-GCE) modified electrode. It is obvious that the presence of exterior AuNPs increases both the electrode conductivity and the active surface area.

Figure 3(B) depicts the electrochemical behavior of bare GCE (solid black) and as-prepared modified electrodes Ptyr-GCE (solid red) and AuNPs.Ptyr-GCE (dotted blue), respectively, in the presence of a redox probe (5 mM of $\left.\left[\mathrm{Fe}(\mathrm{CN})_{6}\right]^{3-14}\right)$ using the $\mathrm{CV}$ method. Both bare GCE and AuNPs.Ptyr-GCE produce very well-defined and comparable reversible redox waves with peak potential separation $\left(\Delta E_{\mathrm{p}}=E_{\mathrm{p}, \mathrm{a}}-E_{\mathrm{p}, \mathrm{c}}\right)$ of $106 \mathrm{mV}$ and $188 \mathrm{mV}$, respectively. In the case of Ptyr-GCE, the calculated $\left(\Delta E_{\mathrm{p}}=282 \mathrm{mV}\right)$ value becomes much larger due to the evident potential shift (far positive and negative) of both anodic and cathodic peaks, suggesting slow electrode kinetics. The presence of AuNPs 
onto the Ptyr moiety improves the electron transfer process by lowering the electrode over-potential by approximately $100 \mathrm{mV}$. Moreover, the response currents (anodic and cathodic) of the AuNPs.Ptyr modified surface are much greater than that recorded for the virgin Ptyr surface, consisting with the experimental data of EIS presented in Figure 3(A). The above characteristic mapping confirms a successful construction of modified electrodes and the importance of AuNPs as a reactive dopant. A further investigation on the behavior of NOR oxidation at various electrodes was conducted to characterize the significance of AuNP doped surface materials.

Figure 4 depicts the electrochemical oxidation of $50 \mu \mathrm{M}$ NOR at various electrodes in $0.1 \mathrm{M}$ of $\mathrm{PBS}(\mathrm{pH}=7.4)$ and $(v=50 \mathrm{mV} / \mathrm{s})$ using the DPV technique. The electrochemical measurements were expressed by the change in the current response of NOR oxidation $(\Delta I)$ after eliminating the current response of the background electrolyte generated by each electrode. Obviously, the current response at the bare GCE is the lowest compared to the as-prepared modified electrodes which can be attributed to weak adsorption of NOR. In the intermediate (Ptyr-GCE) surface, the current response is little higher than the bare substrate due to the presence of more active surface sites to attract NOR. The proposed sensor (AuNPs.Ptyr-GCE) shows a prominent current response approaching 1.75 times greater than that of the (Ptyr-GCE) modified electrode. The presence of AuNPs has an evident synergism action for accelerating the electron transfer process with NOR and also offers a wide adsorption assembled surface for stronger bonding. It should be noted that the peak potential of NOR oxidation is shifted in a more negative direction by $25 \mathrm{mV}$ compared to the modified Ptyr-GCE. It is good evidence for a rapid electrochemical reaction that is explicitly pertinent to the surface materials of the proposed sensor.

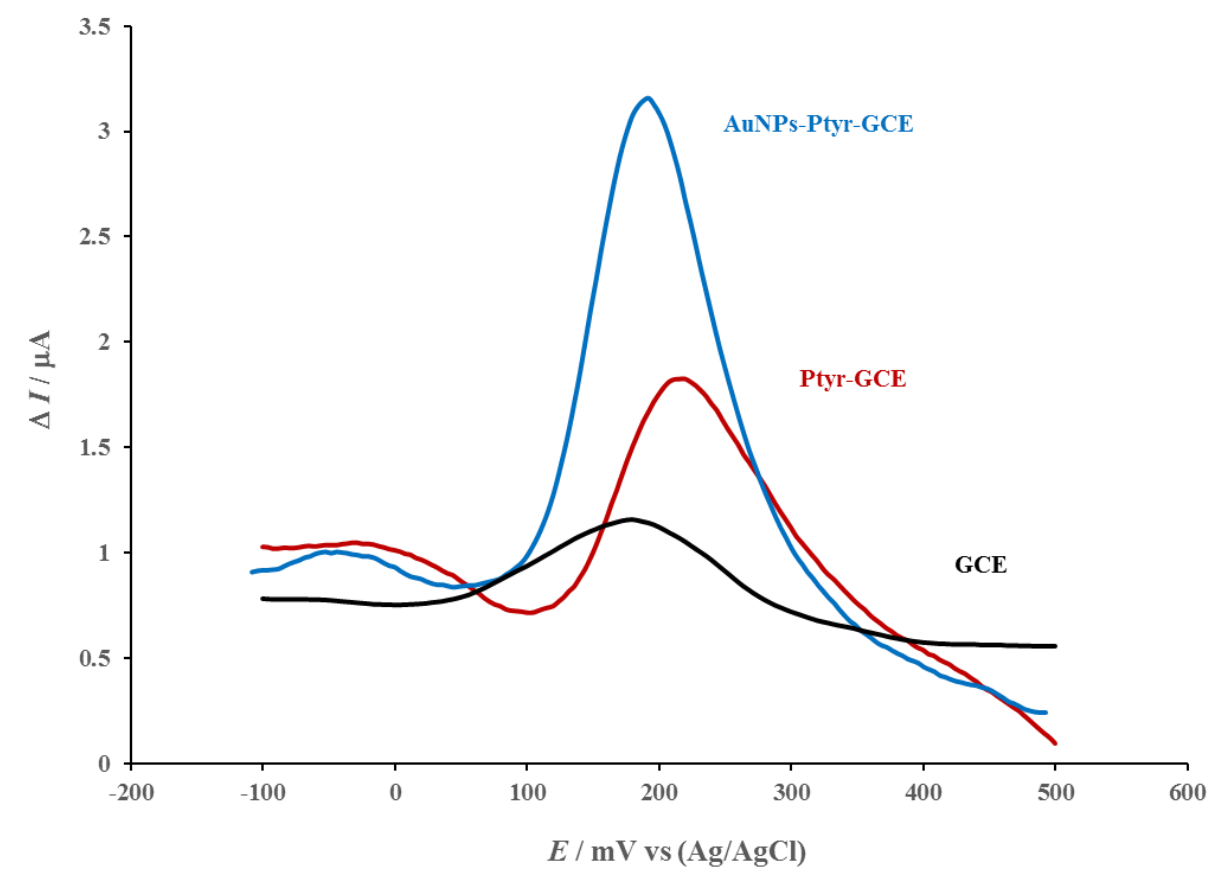

Figure 4. DPV current responses at $50 \mathrm{mV} / \mathrm{s}$ for the oxidation of $50 \mu \mathrm{M}$ NOR in $0.1 \mathrm{M} \mathrm{PBS}(\mathrm{pH}=7.4)$ recorded at bare GCE (black), Ptyr-GCE (red) and AuNPs.Ptyr-GCE (blue).

\subsubsection{The behavior of NOR oxidation at AuNPs.Ptyr-GCE}

The electrochemical behavior of NOR at the developed AuNPs.Ptyr-GCE was monitored using the cyclic voltammetry (CV) technique as shown in Figure 5 (A). Apparently, the reaction mechanism of NOR is following an irreversible mode concluded by the growth of an anodic peak at $240 \mathrm{mV}$ in the forward scan corresponding to NOR oxidation, which increases linearly with increasing [NOR]. In the reverse cathodic scan, only a peak shoulder of constant current response is collected at $130 \mathrm{mV}$ for the entire [NOR] range. This trend can be attributed to the reaction mechanism of NOR oxidation which involves a cyclization step [37]. It is important to note that some literature reports that NOR experiences a reversible reaction by varying the recorded anodic and cathodic peaks with electrode scan rates without considering the size (ratio) of both obtained peaks.

Figure 5 (B) depicts the linear relationship of the anodic peak current $\left(I_{\mathrm{p}}\right)$ as a function of [NOR] collected from the basic experimental data of Figure 5 (A). The resulting slope of $(0.0577 \mu \mathrm{A} / \mu \mathrm{M})$ is important to calculate the diffusion coefficient of NOR applying the Randles-Sevcik equation for irreversible processes [36]. The calculated value is $7.39 \times 10^{-5} \mathrm{~cm}^{2} / \mathrm{s}$ assuming a transfer of two electrons $(\mathrm{n}=2)$ by NOR oxidation. The obtained value for the present system is approximately two times greater than $\left(3.30 \times 10^{-5} \mathrm{~cm}^{2} / \mathrm{s}\right)$ evaluated at a ZnO/CNTs modified electrode [38]. 


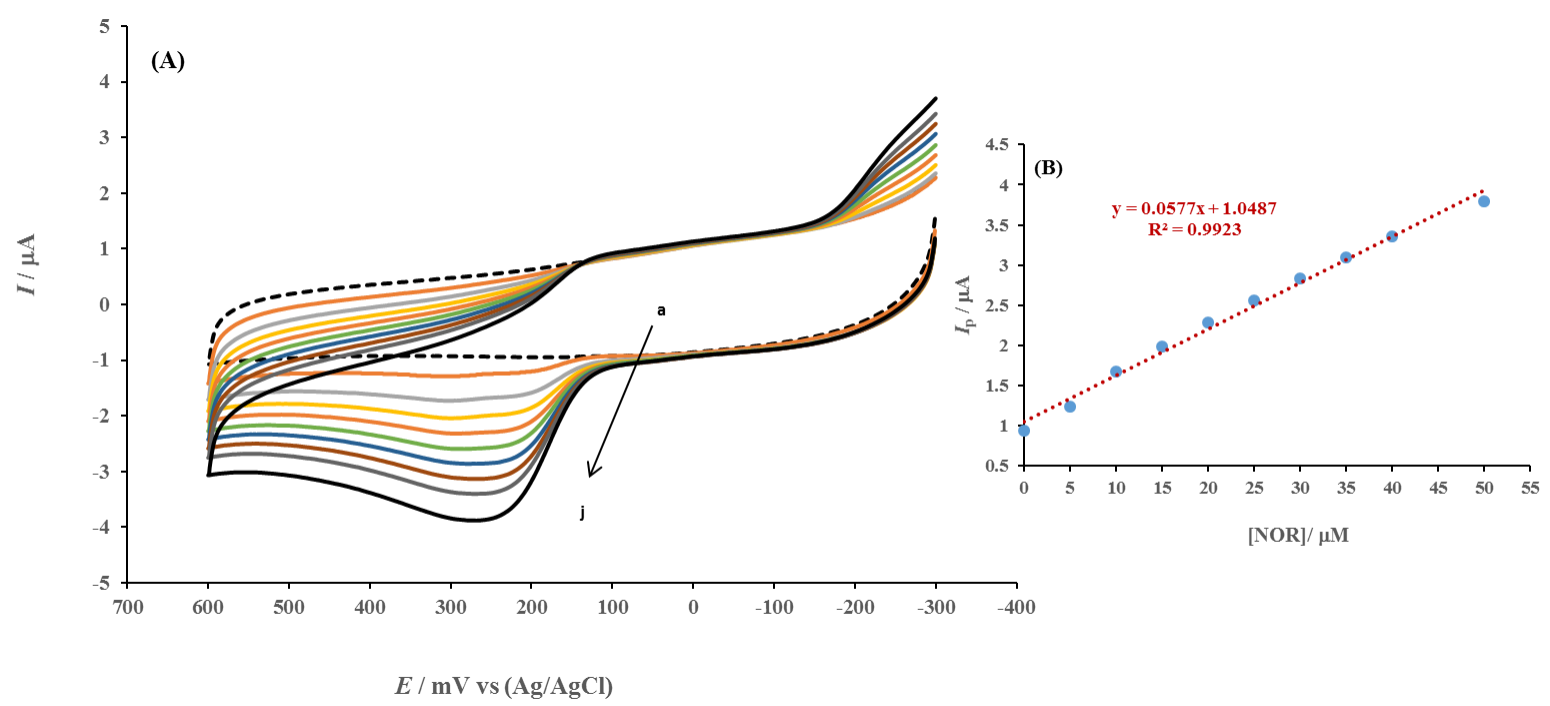

Figure 5. (A) CV waves for the behavior of NOR at AuNPs.Ptyr-GCE ( $v=50 \mathrm{mV} / \mathrm{s})$ in PBS (pH = 7.4) recorded for a range of [NOR]; (a) 0, (b) 5, (c) 10, (d) 15, (e) 20, (f) 25, (g) 30, (h) 35, (i) 40, and (j) $50 \mu \mathrm{M}$. (B) The linear relationship of $I_{\mathrm{p}}$ vs $[\mathrm{NOR}]$ of the original DPV data presented in Fig. 5 (A).

The minimum and maximum boundaries of NOR diffusion coefficient values were not identified since this thermodynamic parameter is affected by the electrolyte composition, the nature of surface materials, the ionic or molecular size, and the temperature.

The reactivity of the proposed sensor (AuNPs.Ptyr-GCE) was tested under experimental conditions given in Figure 5 (A) for 10 cycles (20 segments) in the presence of $50 \mu \mathrm{M}$ of NOR. The anodic peak current decreased spontaneously with subsequent cycles to fall to $86.0 \%$ (in the last three cycles) of its ideal initial value as shown in Figure 6. This marks a change in the nature of the surface due to the accumulation of inactive oxidation byproducts. Moreover, it describes the robustness and stability of the developed sensor against surface poisoning. It is worth noting that the oxidative pathway of NOR is initiated by the transfer of two-electrons and two-protons, forming an unstable oquinone derivative that rapidly cyclized via intermolecular attraction to produce a leucochrome derivative. The reaction is propagated to the formation of an electrochemically inactive melanin polymeric species [37, 39].

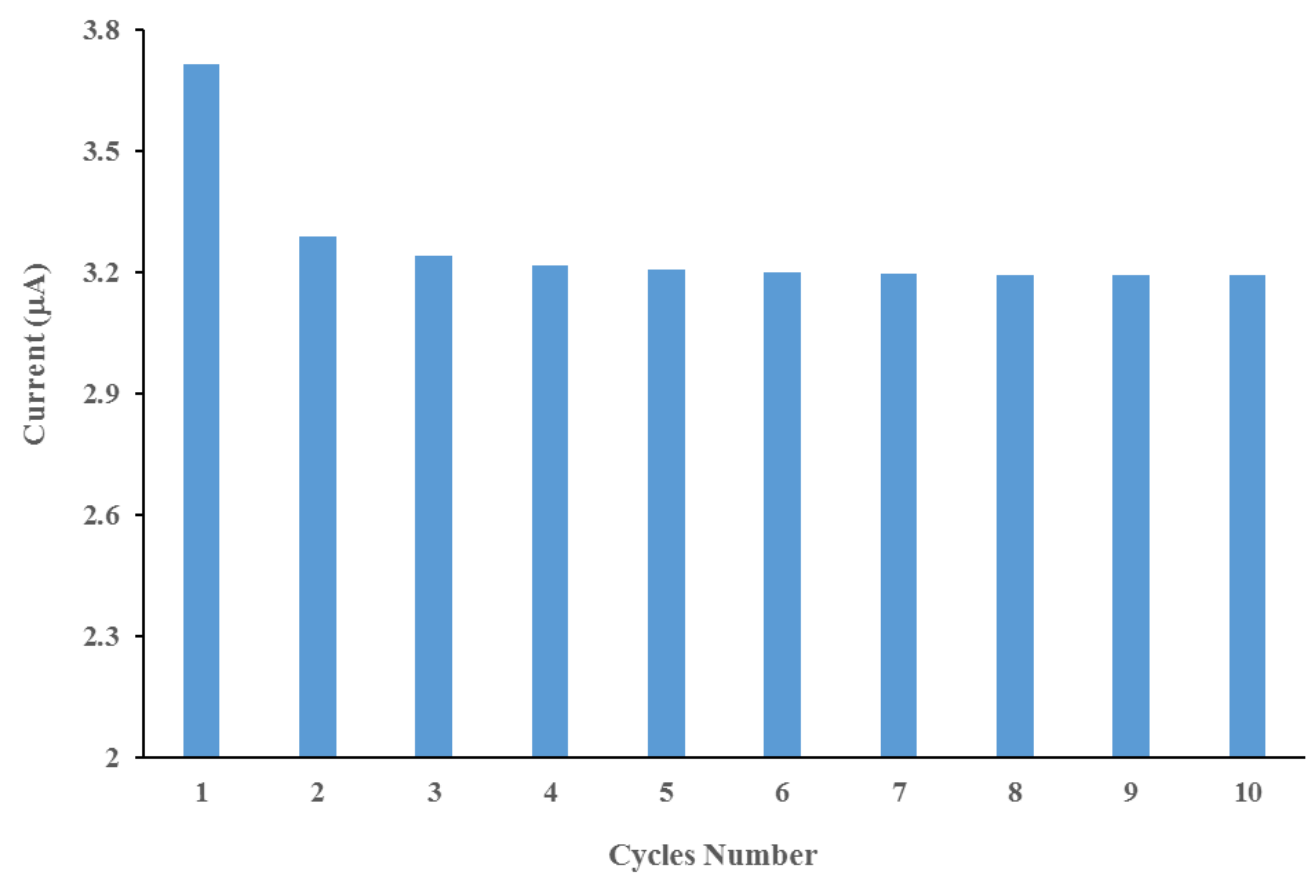

Figure 6. The reactivity test of AuNPs.Ptyr-GCE (current response as a function of repetitive CV cycles) for the oxidation of $50 \mu \mathrm{M}$ NOR in $0.1 \mathrm{M}$ PBS $(\mathrm{pH}=7.4)$. 
<smiles>CCC(CN)c1ccc(O)c(O)c1</smiles>

Norepinephrine<smiles>NCC(O)C1=CC(=O)C(=O)C=C1</smiles>

O-Quinone

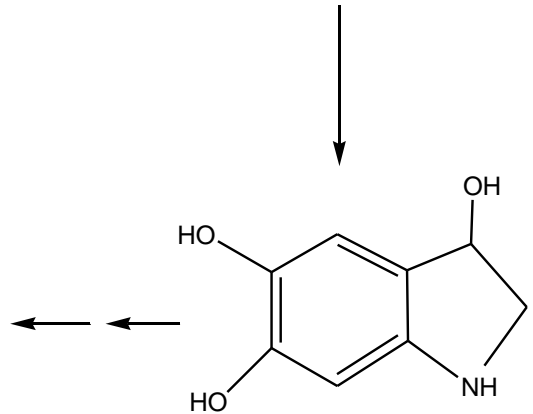

Leucochrome

Scheme 1. The oxidative pathway of NOR describing the cyclization step and end propagation mechanism for the formation of inactive melamine polymer.

\subsubsection{Selective determination of NOR at AuNPs.Ptyr-GCE}

The practical application of AuNPs.Ptyr-GCE for NOR quantification is presented in Figure 7 employing DPV in $0.1 \mathrm{M}$ of PBS $(\mathrm{pH}=7.4)$ at $(v=50 \mathrm{mV} / \mathrm{s})$. A well-defined anodic peak current was obtained at $192 \mathrm{mV} \mathrm{vs} \mathrm{Ag} / \mathrm{AgCl}$ corresponding to NOR oxidation, which directly correlated to successive increments of [NOR]. The stability and reactivity of the sensor is diagnosed by bringing the anodic peak to a constant potential value for the entire applied [NOR] range. The linear plot of $\left(I_{\mathrm{p}}\right)$ as a function of [NOR] shown in the inset of Figure 7 produces a slope of $(0.1189$ $\mu \mathrm{A} / \mu \mathrm{M})$, by which the calculated detection limit $\left(\mathrm{DL}_{3 \sigma}\right)$ was $0.130 \mu \mathrm{M}(22 \mathrm{ppb})$.

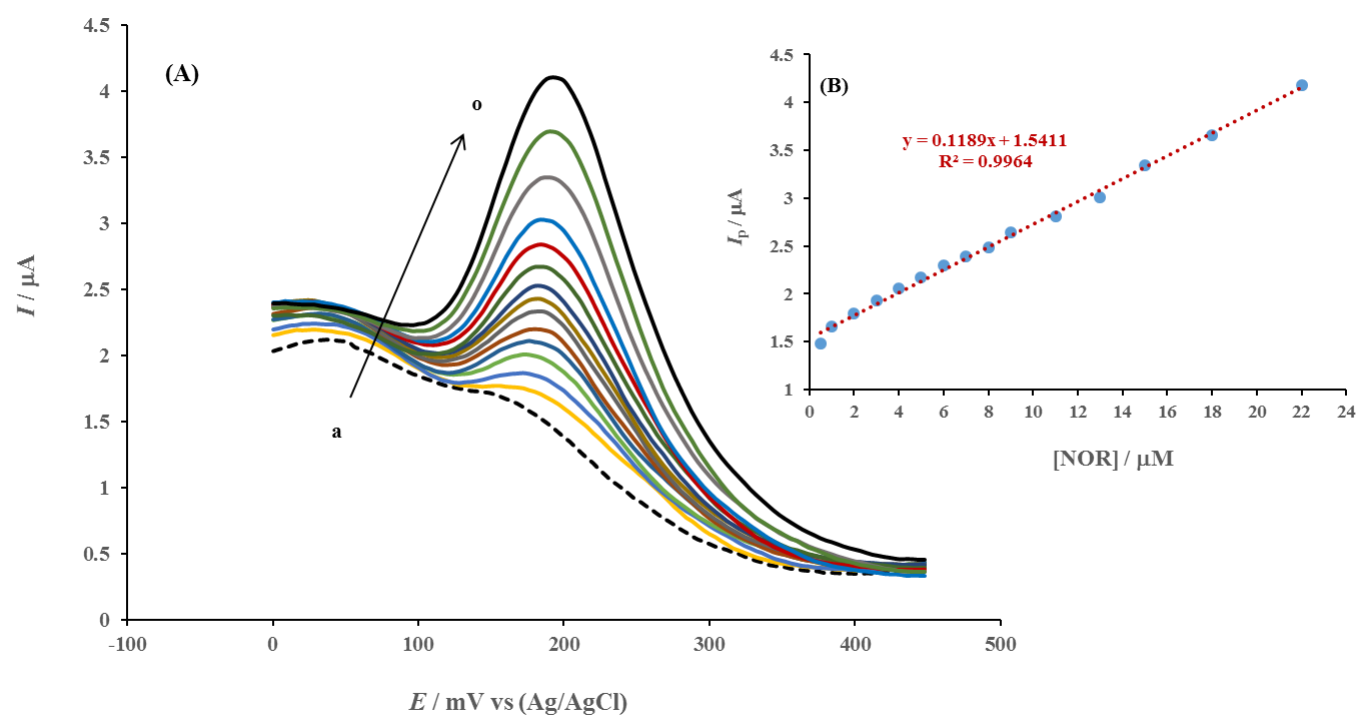

Figure 7. (A) DPV current responses for NOR oxidation at AuNPs.Ptyr-GCE $(v=50 \mathrm{mV} / \mathrm{s})$ in PBS $(\mathrm{pH}=7.4)$ recorded as a function of [NOR]; (a) 0.5, (b) 1, (c) 2, (d) 3, (e) 4, (f) 5, (g) 6, (h) 7, (i) 8, (j) 9, (k) 11, (l) 13, (m) 15, (n) 18 , and (o) $22 \mu \mathrm{M}$. (B) The linear relationship of $I_{\mathrm{p}} \mathrm{vs}[\mathrm{NOR}]$ of the original data presented in Figure 7(A). 
Table 1 lists the analytical performance of various modified electrodes [40-46] for NOR quantification in terms of detection limit, sensitivity and applied electrochemical method. The present electrochemical system is highly competent and exhibits superior performance to some relevant polymeric constituent surfaces.

Inspection of the competency of the proposed sensor was performed by selective determination of NOR in the presence of AA $(250 \mu \mathrm{M})$ and UA $(50 \mu \mathrm{M})$ as electroactive interference species. Figure 8(A) shows the DPV anodic peak for NOR oxidation obtained at $192 \mathrm{mV}$ which increases gradually with subsequent addition of NOR for a concentration range between $0.5 \mu \mathrm{M}$ and $25 \mu \mathrm{M}$. The inset of Figure 8(A) shows that the DPV anodic peaks for AA and UA oxidation (in the absence of NOR) occurred at $2 \mathrm{mV}$ and $266 \mathrm{mV}$, respectively.

Table 1. The analytical performance of various modified electrodes in terms of detection limit, sensitivity and method employed for NOR quantification.

\begin{tabular}{lllll}
\hline $\begin{array}{l}\text { Modified } \\
\text { Electrode }\end{array}$ & $\begin{array}{l}\text { DL } \\
(\mu \mathrm{M})\end{array}$ & $\begin{array}{l}\text { Sensitivity } \\
(\mu \mathrm{A} / \mu \mathrm{M})\end{array}$ & Method & Ref. \\
\hline PDAN/GCE & 1.82 & 0.012 & DPV & {$[\mathbf{4 1 ]}$} \\
Ppy/b-CD-ME & 0.80 & 0.050 & SWV & {$[\mathbf{4 2}]$} \\
BHa and TiO ${ }_{2}$ NPs & 0.50 & 0.199 & DPV & {$[\mathbf{4 3}]$} \\
Poly(Glutamic acid) MCPE & 0.43 & 0.094 & DPV & {$[44]$} \\
CACE/GCE & 0.28 & 0.044 & DPV & {$[45]$} \\
MWNTs-ZnO/Ch-SPE & 0.20 & 0.059 & SWV & {$[\mathbf{4 6 ]}$} \\
Poly(Cresol Red)/GCE & 0.20 & 0.156 & DPV & {$[\mathbf{4 7}]$} \\
AuNPS.Ptyr/GCE & 0.13 & 0.119 & DPV & Present \\
\end{tabular}

A potential distance of $190 \mathrm{mV}$ from AA and $74 \mathrm{mV}$ from UA is adequate to overcome any possible overlap of anodic peaks of the three species. Moreover, the adsorption capacity of the electrode surface materials is capable of assembling all molecules and their byproducts indicating a robust and reactive sensor. A close scrutiny of the linear plot, $\left(I_{\mathrm{p}}\right)$ vs $[\mathrm{NOR}]$, given in Figure $8(\mathrm{~B})$, demonstrates that the slope of $(0.1015 \mu \mathrm{A} / \mu \mathrm{M})$ is consistent with that in the absence of AA and UA (shown above in the insert of Figure 7) which is evidence of good reproducibility and the stability of the present sensor. Moreover, the calculated detection limit ( $\left.\mathrm{DL}_{3 \sigma}\right)$ was $0.142 \mu \mathrm{M}(24 \mathrm{ppb})$. The reliability and sensitivity of the present electrochemical system were tested for the determination of NOR in drug and blood plasma samples using a DPV method as described above in section 2.4 . The average recovery percentage $(n=3)$ of NOR listed in Table 2 was obtained by conversion the DPV peak current into [NOR] using the regression data illustrated in Figure 8(B). The minimum (95\%) and maximum (101\%) of reported percentages under the present experimental conditions describe the extent of reactivity and analytical performance of the sensor developed for sensitive NOR determination.

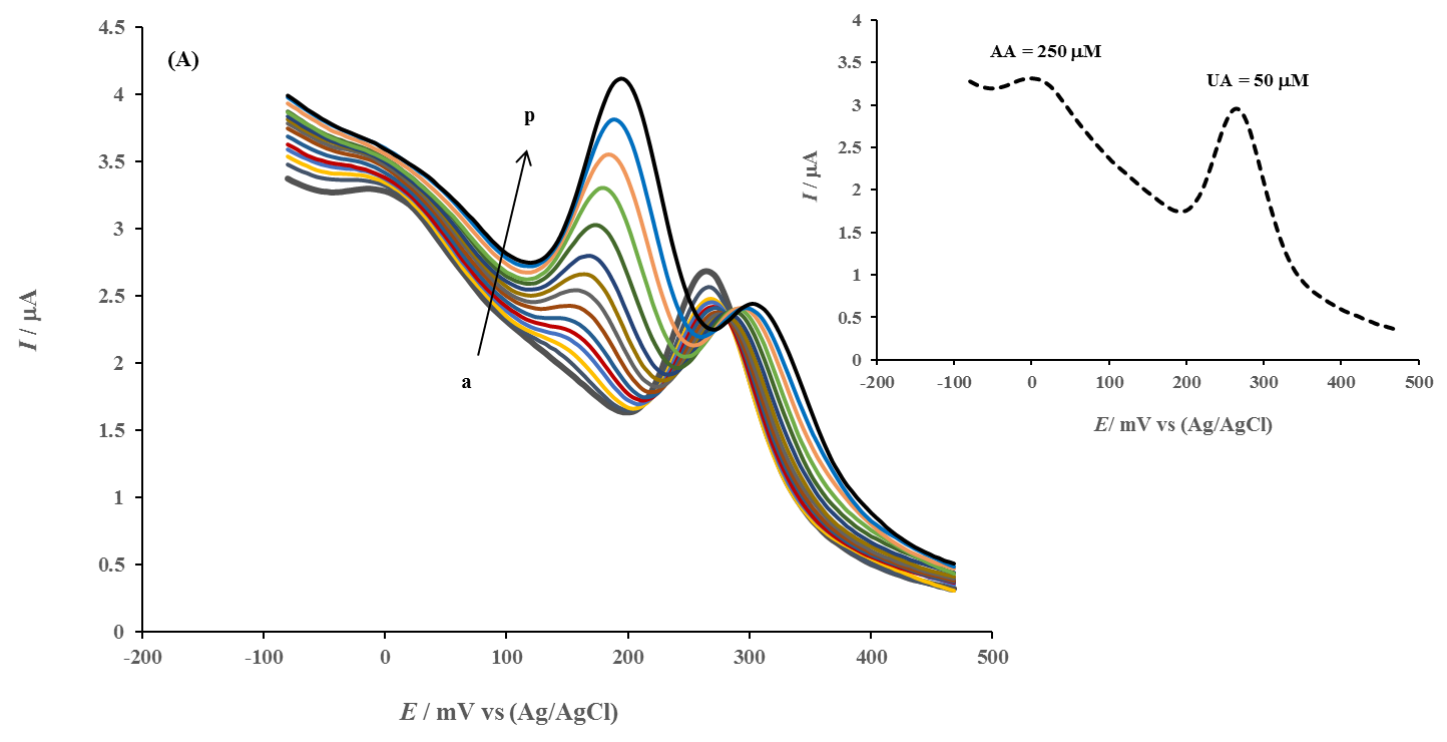




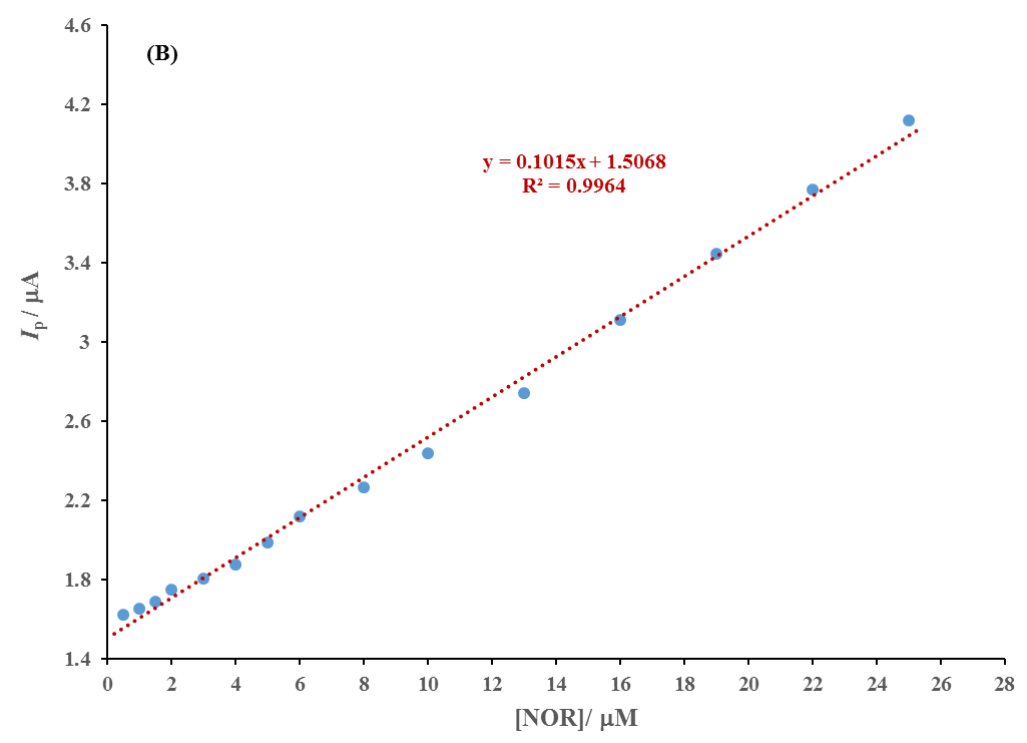

Figure 8. (A) DPV current responses for selective determination of NOR in the presence of $250 \mu \mathrm{M}[\mathrm{AA}]$ and $50 \mu \mathrm{M}$ [UA] at AuNPs.Ptyr-GCE $(v=50 \mathrm{mV} / \mathrm{s})$ in PBS ( $\mathrm{pH}=7.4)$ recorded for a range of [NOR]; (a) 0.5, (b) 1, (c) 1.5 , (d) 2, (e) 3, (f) 4, (g) 5, (h) 6, (i) 8, (j) 10, (k) 13, (1) 16, (m) 19, (n) 22, and (o) $25 \mu \mathrm{M}$. Insert is the DPV response in the absence of NOR. (B) The linear relationship of $I_{\mathrm{p}} \mathrm{vs}[\mathrm{NOR}]$ of the original DPV data presented in Figure 8 (A).

Table 2. The recovery percentage of NOR in pharmaceutical ampoule and plasma blood samples.

\begin{tabular}{llll}
\hline Samples $(\mu \mathrm{M})$ & {$[$ Actual $]$} & $\begin{array}{l}{\left[\text { Found } \pm \mathrm{RSD}^{(\mathbf{a})}\right.} \\
(\mu \mathrm{M})\end{array}$ & $\begin{array}{l}\text { Recovery } \\
(\%)\end{array}$ \\
\hline Ampoule & & & \\
\hline$(1)$ & 0.591 & $0.565 \pm 0.021$ & 95.6 \\
$(2)$ & 1.182 & $1.150 \pm 0.027$ & 97.3 \\
$(3)$ & 2.364 & $2.327 \pm 0.035$ & 98.4 \\
$(4)$ & 4.728 & $4.783 \pm 0.028$ & 101.2 \\
$(5)$ & 9.456 & $9.464 \pm 0.019$ & 100.1 \\
Plasma & & & ------ \\
$(1)$ & 0.00 & N.D. & 95.0 \\
$(2)$ & 0.50 & $0.475 \pm 0.017$ & 95.6 \\
$(3)$ & 1.00 & $0.956 \pm 0.026$ & 99.3 \\
$(4)$ & 3.00 & $2.980 \pm 0.029$ & 101.5 \\
$(5)$ & 6.00 & $6.092 \pm 0.034$ & 100.8 \\
$(6)$ & 9.00 & $9.068 \pm 0.034$ & \\
\hline
\end{tabular}

(a) Relative Standard Deviation $(\mathrm{n}=3)$.

The electrochemical stability of the developed sensor in the last injection of NOR $(25 \mu \mathrm{M})$ NOR in the presence of $(250 \mu \mathrm{M} \mathrm{AA})$ and $(50 \mu \mathrm{M}$ UA) was verified by DPV repetitive scanning for 12 runs with 5 min intervals. The anodic peak potential of NOR oxidation was consistently obtained at $192 \mathrm{mV}$ and decreased negligibly with subsequent runs to approach $2.6 \%$ of its maxima in the last run, suggesting a reliable and stable sensor for selective NOR quantification in real samples.

\section{Conclusion}

This paper describes an approach for the fabrication of a solid-state sensor based on electrochemical polymerization of tyramine (Ptyr) film onto the surface of a glassy carbon electrode (GCE) followed by a drop casting of gold nanoparticles (AuNPs). The as-prepared surface materials (AuNPs, Ptyr-GCE) were characterized using surface image spectroscopy and electrochemical methods. These comprehensive investigative methods explore properties of the built up surface materials such as composition and structure, resistivity and reactivity, and analytical 
performance. The proposed sensor was tested for norepinephrine (NOR) determination in an artificial sample at which the limit of detection was brought down to $0.130 \mu \mathrm{M}$. The sensor excellently passed the selectivity test in the presence of excess concentrations of electro-active biological interference agents such as ascorbic acid (AA) and uric acid (UA). Moreover, the sensor's performance was substantiated practically for NOR determination in a drug formulation and in plasma blood samples with satisfactory recovery percentages.

\section{Conflict of interest}

The authors declare no conflict of interest.

\section{Acknowledgement}

The authors would like to thank Sultan Qaboos University (SQU), Sultanate of Oman, for supporting this work by the research grant number (IG/SCI/CHEM/18/01). Many thanks to Sultan Qaboos University Hospital (SQUH) for providing a NOR injection ampoule and plasma blood sample.

\section{References}

1. Geise, R.J., Adams, J.M., Barone, N.J., Yacynych, A.M., Electropolymerized films to prevent interferences and electrode fouling in biosensors, Biosensors and Bioelectronics 1991, 6, 151-160.

2. Ambrosi, A., Morrin, A., Smyth, M.R., Killard, A.J., The application of conducting polymer nanoparticle electrodes to the sensing of ascorbic acid, Analytica Chimica Acta 2008, 609, 37-43.

3. Emr, S.A., Yacynych, A.M., Use of polymer films in amperometric biosensors, Electroanalysis 1995, 7, 913-923.

4. Miao, Y., Chen, J., Hu, Y., Electrodeposited nonconducting polytyramine for the development of glucose biosensors, Analytical Biochemistry 2005, 339, 41-45.

5. Miscoria, S.A., Barrera, G.D., Rivas, G.A., Glucose biosensors based on the immobilization of glucose oxidase and polytyramine on rodhinized glassy carbon and screen printed electrodes, Sensors and Actuators B: 2006, 115, 205-211. 6. Wu, Z.S., Li, J.S., Deng, T., Luo, M.H., Shen, G.L., Yu, R.Q., A sensitive immunoassay based on electropolymerized films by capacitance measurements for direct detection of immune species, Analytical Biochemistry 2005, 337, 308-315.

7. Tran, L.D., Piro, B., Pham, M.C., Ledoan, T., Angiari, C., Dao, L.H., Teston, F., A polytyramine film for covalent immobilization of oligonucleotides and hybridization, Synthetic Metals 2003, 139, 251-262.

8. Situmorang, M., Gooding, J.J., Hibbert, D.B., Barnet, D., Electrodeposited polytyramine as an immobilization matrix for enzyme biosensors, Biosensors and Bioelectronics 1998, 13, 953-962.

9. Tenreiro, A.M., Nabais, C., Correia, J.P., Fernandes, F.M.S., Romero, J.R., Abrantes, L.M., Progress in the understanding of tyramine electro-polymerization mechanism, Journal of Solid State Electrochemistry 2007, 11, 10591069.

10. de Castro, C.M., Vieira, S.N., Goncalves, R.A., Brito-Madurro, A.G., Madurro, J.M., Electrochemical and morphologic studies of nickel incorporation on graphite electrodes modified with polytyramine, Journal of Materials Science 2008, 43, 475-482.

11. Khudaish, E.A., Al-Ajmi, K., Al-Harthi, S., Al-Hinai, A., A solid state sensor based polytyramine film modified electrode for the determination of dopamine and ascorbic acid in a moderately acidic solution, Journal of Electroanalytical Chemistry 2012, 676, 27-34.

12. Cui, F., Zhang, X., Electrochemical sensor for epinephrine based on a glassy carbon electrode modified with graphene/gold nanocomposites, Journal of Electroanalytical Chemistry 2012, 669, 35-40.

13. Du, J., Yue, R., Ren, F., Yao, Z., Jiang, F., Yang, P., Du, Y., Simultaneous determination of uric acid and dopamine using a carbon fiber electrode modified by layer-by-layer assembly of graphene and gold nanoparticles, Gold Bulletin 2013, 46, 137-144.

14. Sorouraddin, M.H., Manzoori, J.L., Kargarzadeh, E., Haji Shabani, A.M., Spectrophotometric determination of some catecholamine drugs using sodium bismuthate, Journal of Pharmaceutical and Biomedical Analysis 1998, 18, 877-881.

15. Lechin, F., van der Dijs, B., Lechin, A.E., Circulating Serotonin, Catecholamines, and Central Nervous System Circuitry Related to Some Cardiorespiratory, Vascular, and Hematological Disorders, Journal of Applied Research 2005, 5, 605-621.

16. McEwen, B.S., Interacting mediators of allostasis and allostatic load: towards an understanding of resilience in aging, Metabolism 2003, 52, 10-16.

17. Sheikh, S., Ejazul Haque, S., Mir, S.S., Neurodegenerative Diseases: Multifactorial Conformational Diseases and Their Therapeutic Interventions, Journal of Neurodegenerative and Disease 2013, 8, 563481 (8 pages).

18. Gibbs, M.E., Summers, R.J., Role of adrenoceptor subtypes in memory consolidation, Progress in Neurobiology 2002, 67, 345-391.

19. Song, Y., Theoretical study on the electrochemical behavior of norepinephrine at Nafion multi-walled carbon nanotubes modified pyrolytic graphite electrode, Spectrochimica Acta A: 2007, 67, 1169-1177. 
20. Carney, R.M., Freedland, K.E., Veith, R.C., Cryer, P.E., Skala, J.A., Lynch, T., Jaffe, A.S., Major depression, heart rate, and plasma norepinephrine in patients with coronary heart disease, Biological Psychiatry 1999, 45, 458-463.

21. Rommelfanger, K.S., Weinshenker, D., Norepinephrine: The red headed step child of Parkinson's disease, Biochemical Pharmacology 2007, 74, 177-190.

22. Fotopoulou, M. A., Ioannou, P. C., Post-column terbium complexation and sensitized fluorescence detection for the determination of norepinephrine, epinephrine and dopamine using high-performance liquid chromatography, Analytica Chimica Acta 2002, 462, 179-185.

23. Kuhlenbeck, D. L., O’Neill, T. P., Mack, C. E., Hoke, S. H., Wehmeyer, K. R., Determination of norepinephrine in small volume plasma samples by stable-isotope dilution gas chromatography-tandem mass spectrometry with negative ion chemical ionization, Journal of Chromatography B: 2000, 738, 319-330.

24. Luczak, T., Determination of norepinephrine alone and in the presence of ascorbic and uric acids using a gold electrode modified with gold nanoparticles and self-assembled layers of meso-2,3-dimercaptosuccinic acid, Electroanalysis 2014, 26, 1461-1470.

25. Lavanya, N., Sekar, C., Electrochemical sensor for simultaneous determination of epinephrine and norepinephrine based on cetyltrimethylammonium bromide assisted $\mathrm{SnO}_{2}$ nanoparticles, Journal of Electroanalytical Chemistry 2017 , 801, 503-510.

26. Chen, J., Huang, H., Zeng, Y., tang, H., Li, L., A novel composite of molecularity imprinted polymer-coated PdNPs for electrochemical sensing norepinephrine, Biosensors and Bioelectronics 2015, 65, 366-374.

27. Lavanya, N., Sekar, C., Electrochemical sensor for simultaneous determination of epinephrine and norepinephrine based on cetyltrimethylammonium bromide assisted $\mathrm{SnO}_{2}$ nanoparticles, Journal of Electroanalytical Chemistry 2017, 801, 503-510.

28. Mukdasai, S., Langsi, V., Pravda, M., Srijaranai, S., Glennon, J.D., A highly sensitive electrochemical determination of norepinephrine using L-cysteine self-assembled monolayers over gold nanoparticles/multi-walled carbon nanotubes electrode in the presence of sodium dodecyl sulfate, Sensors and Actuators B: 2016, 236, $126-135$.

29. Ma, X., Chao, M., Chen, M., Simultaneous electrochemical determination of norepinephrine, ascorbic acid and uric acid using a graphene modified glassy carbon electrode, Russian Journal of Electrochemistry 2014, 50, $154-161$.

30. Ferreira, M., Varela, H., Torresi, R.M., Tremiliosi-Filho, G., Electrode passivation caused by polymerization of different phenolic compounds, Electrochimica Acta 2006, 52, 434-442.

31. Tenreiro, A.M., Nabais, C., Correia, J.P., Fernandes, F.M.S., Romero, J.R., Abrantes, L.M., Progress in the understanding of tyramine electro-polymerization mechanism, Journal of Solid State Electrochemistry 2007, 11, 10591069.

32. de Castro, C.M., Vieira, S.N., Goncalves, R.A., Brito Madurro, A.G., Madurro, J.M., Electrochemical Morphologic Studies of Nickel Incorporation on Graphite Electrodes Modified with Polytyramine, Journal of Materials Science 2008, 43, 475-482.

33. Spataru, T., Marcu, M., Banu, A., Roman, E., Spataru, N., Electrodeposition of platinum on polytyramine-modified electrodes for electrocatalytic applications, Electrochimica Acta 2009, 54, 3316-3319.

34. Brust, M., Walker, M., Bethell, D., Schiffrin, D.J., Whyman, R., Synthesis of thiol derivatized gold nanoparticles in a two-phase liquid-liquid system, J. Chemical Society Chemical Communications 1994, 7, 801-802.

35. Casaletto, M.P., Longo, A., Martorana, A., Prestianni, A., Venezia, A.M., XPS study of supported gold catalysts: the role of $\mathrm{Au}^{0}$ and $\mathrm{Au}^{+\delta}$ species as active sites, Surface and Interface Analysis 2006, 38, 215-218.

36. Finklea H.O., Snider D.A., Fedyk J., Sabatani E., Gafni Y., Rubinstein I., Langmuir 1993, 9, 3660-3667.

37. Bard, A.J., Faulkner, L.R., Electrochemical Methods: Fundamentals and Applications, Second Edition, Wiley, 2001, (Chapter Three, pages 98 -103) and (Chapter Six. Page 236)

38. Manini, P., Panzella, L., Napolitano, A., d'Ischia, M., Oxidation chemistry of norepinephrine: Partitioning of the oquinone between competing cyclization and chain breakdown pathways and their roles in melanin formation, Chemical Research in Toxicology 2007, 20, 1549-1555.

39. Pahlavan, A., Gupta, V.K., Sanati, A.L., Karimi, F., Yoosefian, M., Ghadami, M., ZnO/CNTs nanocomposite/ionic liquid carbon paste electrode for determination of noradrenaline in human samples, Electrochimica Acta 2014, 123, 456-462.

40. Manini, P., Pezzella, A., Panzella, L., Napolitano, A., d’Ischia, M., New insight into the oxidative chemistry of noradrenaline: Competitive o-quinone cyclisation and chain fission routes leading to an unusual 4-[bis-(1H-5,6dihydroxyinol-2-yl) methyl]-1,2-dihydroxy benzene derivative, Tetrahedron 2005, 61, 4075-4080.

41. da Silva, Q.G., Barbosa, N.V., de Pieri Troiani, E., Faria, R.C., Electrochemical determination of norepinephrine on cathodically pretreated poly(1,5-diaminonaphthalene) modified electrode, Electroanalysis 2011, 23, $1359-1364$.

42. Izaoumen, N., Buchta, D., Zejli, H., Kaouttit, M.E., Temsamani, K.R., The electrochemical behavior of neurotransmitters at a poly(pyrrole- $\beta$-cyclodextrin) modified glassy carbon electrode, Analytical Letters 2005, 38, 1869-1885.

43. Ardakani, M.M., Beitollahi, H., Mohseni, M.S., Naeimi, H., Taghavinia, N., Novel nanostructure electrochemical sensor for electrocatalytic determination of norepinephrine in the presence of high concentrations of acetaminophene and folic acid, 2010, 378, 195-201.

44. Ganesh, P.S., Swamy, B.E., Simultaneous electroanalysis of norepinephrine, ascorbic acid anduric acid using poly(glutamic acid) modified carbon paste electrode, Journal of Electroanalytical Chemistry 2015, 752, $17-24$. 


\section{A SURFACE NETWORK BASED ON POLYTYRAMINE/GOLD NANOPARTICLES}

45. Zhang, H-L., Liu, Y., Lai, G-S., Yu, A-M., Huang, Y-M., Jin, C.M., Calix[4]arene crown-4 ether modified glassy carbon electrode for electrochemical determination of norepinephrine, Analyst 2009, 134, 2141-2146.

46. Wang, Y., Wang, S., Tao, L., Min, Q., Xiang, J., Wang, Q., Xie, J., Yue, Y., Wu, S., Li, X., Ding, H., A disposable electrochemical sensor for simultaneous determination of norepinephrine and serotonin in rat cerebrospinal fluid based on MWNTs-ZnO/chitosan composites modified screen-printed electrode, Biosensors and Bioelectronics 2015, 65, 3138 .

47. Chen, W., Lin, X., Luo, H., Huang, L., Electrocatalytic oxidation and determination of norepinephrine at poly(cresol red) modified glassy carbon electrode, Electroanalysis 2005, 17, 941-944.

Received 7 September 2020

Accepted 20 January 2021 